\section{Guimarães Rosa}

é uma pérola

perfeita: carta

ao Doutor

Dominique

Fernandez

\section{RESUMO}

Relato de viagem, o livro 0 ouro dos Trópicos: Passeios pelo Portugal e o Brasil Barroco, de Dominique Fernandez, aventura-se também pelas searas da crítica literária. Embora considere Grande Sertão: Veredas, de Guimarães Rosa, a obra máxima da literatura brasileira, Fernandez lamenta e tenta interpretar o que chama de "desfecho artificial" do romancista brasileiro, que revela Diadorim como mulher, descaracterizando, assim, o cunho homossexual da paixão de Riobaldo. Este ensaio, cuja introdução toma a forma de uma carta ao autor francês, aposta na idéia de que a trajetória de Riobaldo não se funda em certezas. Para além das ilações cartesianas, de fato, o Brasil é barroco e a narrativa de Guimarães Rosa é uma pérola perfeita.

\section{ABSTRACT}

A travel report, the book 0 ouro dos Trópicos: Passeios pelo Portugal e 0 Brasil Barrocos, by Dominique Fernandez, aims to be a literary critique too. Although the author thinks that Grande Sertão: Veredas, by Guimarães Rosa, is one of the best works of the Brazilian literature, he regrets, and tries to explain what he calls "an artificial ending": the Brazilian novelist denies the homosexual nature of Riobaldo's love by revealing that his Diadorim was a woman. This essay, whose introduction assumes the form of a letter to that French author, bets on the idea that Riobaldo's trajectory is not based upon certainty. Notwithstanding any Cartesians inferences, Brazil is, in fact, baroque and Guimarães Rosa's narrative is a perfect pearl.

PALAVRAS-CHAVE/KEY-WORDS

- Narrativa (Narrative)

- Literatura (Literature)

- Comunicação (Communication)

\section{Ana Luiza Coiro Moraes}

Mestranda em Comunicação Social - PUCRS

\section{A carta propriamente dita}

Nonada. O diabo Não há! É o que eu digo, se for... Existe é homem humano. Travessia. ${ }^{1}$ Assim falou Riobaldo. O senhor que é escritor e além de tudo francês - portanto, para nós sertanejos do mundo, doutor -, não pensa da mesma maneira? Ah, é verdade, o senhor afirma que negar a evidência, apagar a imagem do diabo quando ele mostra a cara, parece ser um velho hábito no Brasil. ${ }^{2}$ Mas essa conciliação de antíteses não é a própria alma do barroco?

E se o diabo se apresenta na pele de uma mulher, travestida em homem, para melhor guerrear (o que, se sabe, é tarefa de macho) e, pior, para enredar nosso herói Riobaldo nas brumas de uma atração de natureza homossexual (DIADORIM É MINHA NEBLINA)? Culpa-se a profissão do autor, como fez o senhor em sua palestra no III Seminário Internacional de Comunicação (Porto Alegre, 1999)?

Pouco provável que o fato de ser diplomata inibisse Guimarães Rosa de escrever um romance dos transes e angústias da transgressão sexual, ${ }^{3}$ se assim o desejasse. Veja o senhor, doutor, que como cônsul brasileiro em Hamburgo enfrentou maior perigo ao proporcionar asilo no edifício do consulado a judeus perseguidos pela Gestapo; em 1942, quando o Brasil declarou guerra à Alemanha, o escritor chegou a ficar detido por vários meses em Baden-Baden. Quem conta essa história é Günter Lorenz (1973: 315), que em entrevista com Guimarães 
Rosa, ao perguntar-Ihe sobre o feito, recebeu a seguinte resposta:

(...) um diplomata é um sonhador e por isso pude exercer essa profissão. O diplomata acredita que pode remediar o que os políticos arruinaram. Por isso agi daquela forma e não de outra. $E$ também por isso mesmo gosto de ser diplomata. E agora o que houve em Hamburgo é preciso acrescentar mais alguma coisa. Eu, o homem do sertão, não posso presenciar injustiças. No sertão, num caso desses imediatamente a gente saca o revólver, e lá isso não era possível. Precisamente por isso idealizei um estratagema diplomático, e não foi assim tão perigoso. (Lorenz, 1973: 333-334)

Aliás, Lorenz também registra em seu livro, além das diversas entrevistas com os autores latino-americanos sobre quem escreve, o cuidado que teve o tradutor alemão de Grande Sertão: Veredas, em inúmeros encontros com Guimarães, para decifrar as exatas palavras de Riobaldo. Talvez sua leitura da obra tivesse restado mais proveitosa se o tradutor francês, que o senhor com razão critica, não tivesse escrito o que parece um outro romance: o tal de "Diadorim". ${ }^{4}$ Mas, voltando ao caso da negação da homossexualidade de Riobaldo, que o põe irado:

Após ter sido morto em combate, Diadorim é despido para o toalete fúnebre, e descobre-se que é ... uma mulher! Estupefação dolorosa de Riobaldo e, para nós, cólera indignada contra o romancista. O quê! Ele acreditava sinceramente que um amor dessa qualidade só pode ser o que impele um homem para uma mulher? Ou uma pudicícia tardia o teria chamado de volta a uma "ordem moral" que todo o seu livro recusa? Ou ainda o temor da censura o teria incitado a disfarçar uma paixão culposa em dileção permitida? ${ }^{5}$

$O$ doutor desculpe a franqueza, mas temor à censura parece-me argumento frágil, uma vez que $\mathrm{o}$ ato de coragem no serviço diplomático na Alemanha já descarta temores menores. Pudicícia tardia, em irrefletida resolução? Me perdoe o atrevimento - O SENHOR TOLERE, ISTO É O SERTÃo - , mas não é mesmo! Veja o que disse Guimarães Rosa:

Posso permanecer imóvel durante longo tempo, pensando em algum problema e esperar. Nós, sertanejos, somos muito diferentes da gente temperamental do Rio ou da Bahia, que não pode ficar quieta nem um minuto. Somos tipos especulativos, a quem o simples fato de meditar causa prazer. Gostaríamos de tornar a explicar diariamente todos os segredos do mundo. Chocamos o que falamos ou fazemos antes de falar ou fazer. É por isso que normalmente não costumo conversar se antes não posso pensar tranqüilamente e até o final. (...) E também choco meus livros. Uma palavra, uma única palavra ou frase pode me manter ocupado durante horas ou dias. (...) Temos que aprender outra vez a dedicar muito tempo a um pensamento; daí seriam escritos livros melhores. Os livros nascem quando a pessoa pensa; o ato de escrever já é a técnica e a alegria do jogo com as palavras. ${ }^{6}$

E desse jogo, por vezes revelador, dão-se conta aqueles que leram o romance Grande Sertão: Veredas (e não Diadorim), buscando nas palavras a chave para o enigma Maria Deolinda, como atesta Sandra Vasconcelos, via Internet:

Guimarães Rosa traduz esse mundo da oralidade, recuperando a fala arcaizante na construção de sua narrativa escrita, e reitera um procedimento que é característico de sua obra - a intervenção de narrativas no corpo de seu texto 
que, reatualizadas, têm a função de abrir as portas para a revelação do significado daquilo que se narra.

Em Grande Sertão: Veredas há, por exemplo, o conjunto de narrativas que ilustram a narração de Riobaldo, o episódio de Maria Mutema e a Canção de Siruiz - a balada que contém um enigma que, decifrado, pode desvelar a identidade de Diadorim.

E tem mais, doutor: o correspondente do grande jornal paulista (posso imaginar qual seja) mentiu para 0 senhor, provavelmente por total desconhecimento. Ao contrário do que afirmou o jornalista, a sua opinião é (ou foi) compartilhada por aqui. ${ }^{7}$

$\mathrm{Na}$ verdade, esta história do possível homossexualismo de Riobaldo vem sendo discutida por analistas brasileiros há muito tempo. Dacanal (1988: 77-78) anota o "lamentável equívoco" em que teria incorrido a porção da crítica dos anos 60 que reconheceu traços homossexuais no romance e, em não menos redutora análise que a sua (o doutor me desculpe a petulância), engendra esta explicação para a atração de Riobaldo por Diadorim:

Apenas alguém que não leu ou, então, que tresleu a obra de João Guimarães Rosa pode falar da existência de uma problemática homossexual em Riobaldo. Existe, isto sim, um pseudoproblema, originado do fato de uma mulher, travestida de cangaceiro, ter despertado a cobiça sexual em um companheiro de luta. Até quem lê pela primeira vez a obra desconfia da identidade de Diadorim. Mas isto nem vem ao caso. Aceitemos que o leitor descubra apenas na parte final do relato de Riobaldo - a batalha - quem era na realidade Diadorim. E daí? Existe uma problemática homossexual latente em Riobaldo? Ridículo! Até pelo contrário, pois com muito mais razão se pode afirmar que o problema de Riobaldo é o de uma sensibilidade masculina exacerbada a tal ponto que já no primeiro encontro com Diadorim/ menino e, posteriormente, ao conviver com Diadorim/cangaceiro intui, ao contrário dos demais, que Diadorim não é homem. Não interessa - pois este é o pseudoproblema! - que seu consciente não capte as razões de sua inclinação por Diadorim e, enganado pelas aparências, se rebele contra tal tendência, pois assim reage em virtude da repulsa que possui pelo comércio carnal homossexual. Seu faro de macho e sua sensibilidade mais profunda estavam corretos, como fica provado no final.

Descontando-se esses arroubos de preconcito machista, a gente por aqui acha (é, a gente acha, porque as afirmativas americanas estão todas ao norte do continente...) que não é na certeza que se funda a trajetória de Riobaldo.

De fato, a amizade de Riobaldo e Diadorim leva a crer em um amor homossexual. Mas esta narrativa não funciona como sistema lógico-racional: "se Riobaldo sente atração por Diadorim, então ele é homossexual" ou "se Diadorim é, na verdade, Maria Deolinda, então Riobaldo tem faro de macho". O romance latino-americano que a partir dos anos 50 inaugura uma nova estética, convencionalmente chamada de "realismo mágico", é literatura cujas soluções formais desafiam o pensamento simplificador, dissociando-se da lógica linear do relato convencional, de acordo com Chiampi (1980: 21), através de cortes na cronologia fabular, da multiplicidade e simultaneidade dos espaços da ação; caracterização polissêmica das personagens e atenuação da qualificação diferencial do herói; maior dinamismo nas relações entre o narrador e o narratário, o relato e o discurso, através da diversidade das focalizações, da autoreferencialidade e do questionamento da 
instância produtora da ficção.

Trata-se da diferença cultural que o doutor aponta quando comenta a tradução francesa do romance de Guimarães Rosa.

Da mesma forma que para os habitantes de Macondo a produção de gelo é extraordinária e a ascensão aos céus de Remédios, a Bela, é fato corriqueiro, também no sertão a lógica cartesiana inverte-se. Assim como Cem anos de solidão, Grande Sertão: Veredas trabalha com a alteridade da noção de real do romance europeu. $\mathrm{Na}$ concepção de Bella Josef (1989: 284-285), o realismo mágico é literatura que passa a constituir visão total da realidade, o sentido da totalidade que a razão iluminista pretendeu destruir.

Mas o doutor não firmou opinião sobre a questão do CAPIROTO, O QUE-DIGA, que já provocou muita polêmica por aqui. Uns falam de problemática fáustica e outros, dentre os quais se inclui esta sua correspondente, pensam que a trajetória de Riobaldo é despedida do imaginário arcaico do mundo do sertão, identificado por ele, um arrivista, como atrasado e absurdo. Difícil, no entanto, é abandonar crenças ancestrais. Não há certeza em Riobaldo: ao longo do relato, certifica-se com o "doutor" se o diabo, afinal, existe ou não.

Da mesma forma, não há certeza sobre a natureza do afeto de Riobaldo e Diadorim. A análise de tais personagens não deverá ceder a um conhecimento fragmentário, limitador, indigente e redutor da realidade. Não deverá ceder aos modos fundamentais do pensamento simplificador de que fala seu conterrâneo Edgar Morin (s/d:25):

Idealizar (crer que a realidade pode reabsorver-se na idéia, que só o inteligível é real); racionalizar (querer encerrar a realidade na ordem e na coerência dum sistema, proibí-la de transbordar para fora do sistema, precisar justificar a existência do mundo conferindo-lhe um certificado de racionalidade); normalizar (isto é, eliminar o estranho, o irredutível, o mistério).

Seu texto, doutor, embora de deliciosa leitura, a exemplo do que se diz aqui sobre Jorge Amado, o senhor, desculpe o atrevimento (acho que não vou ter coragem de mandar esta carta!), queda-se panfletário ao levantar a bandeira da causa homossexual, reduzindo a transformação de Diadorim em Maria Deolinda numa traição ao orgulho gay.

Não há certezas na transição do arcaico para o moderno. Não há certezas nas dúvidas existenciais de Riobaldo. Não havia certezas no barroco, não há certezas na nova narrativa latino-americana. Não há certezas no Brasil, doutor.

Para uma análise mais proveitosa da literatura brasileira, em especial de Grande Sertão: Veredas, eu penso, melhor seria fazer uso do pensamento complexo, no sentido que Morin (1999: 34) empresta ao termo, e descrer um pouco das próprias crenças. Se sentir é estar distraído, como diz o verso de Fernando Pessoa, então, doutor, que tal distrair-se um pouco do politicamente correto do ideário homossexual, soltar-se das razões da razão da militância gay?

A démarche consiste (...) num ir e vir constantes entre certezas e incertezas, entre o elementar e o global, entre o separável e o inseparável. Ela utiliza a lógica clássica e os princípios de identidade, de não-contradição, de dedução, de indução, mas conhece-lhes os limites e sabe que, em certos casos, deve transgredí-los. Não se trata, portanto, de abandonar os princípios de ordem, de separabilidade e de lógica - mas de integrá-los numa concepção mais rica.

Assim, despeço-me e se o doutor tiver mais um pouco de paciência, leia, a seguir, o trabalho que escrevi e apresentei a seu amigo Juremir. A partir da análise de seu livro O ouro dos trópicos, em especial sobre sua crítica a Grande Sertão: Veredas, trato o tema em três segmentos: O Brasil é 
barroco!, que historia o ciclo do processo criador no Brasil do barroco à pósmodernidade, fundamentado teoricamente pelo pensamento crítico de Affonso Ávila; O novo no arcaico, que analisa as inovações de linguagem, temática, estrutura narrativa e gênero em Grande sertão: veredas, e Civilização oral, com o auxílio da conceituação de "nova narrativa épica no Brasil", de José Hildebrando Dacanal. Anexo, alguns dados biográficos do escritor e um poema sobre seus mistérios: Um chamado João, de Carlos Drummond de Andrade. Recurso metodológico? Só podia ser o amétodo, de Edgar Morin. É O DIABO NA RUA, NO MEIO DO REDEMUNHO...

P.S. - A peça Fool for love, de Sam Sheppard, drama sobre a atração sexual entre dois irmãos, inicia-se com as palavras de um reverendo norte-americano (desculpe a falta de referência, mas estou citando de memória, o doutor releve, é coisa de brasileira...):

Quanto ao amor, não há nada a fazer.

\section{O Brasil é barroco!}

A linha condutora do barroco ao pósmodernismo no Brasil já havia sido traçada pela crítica brasileira, pelo menos no tocante à literatura, de maneira mais consistente que o misto de deslumbramento e desconhecimento encontrado na obra de Dominique Fernandez.

Exemplo desse pensamento crítico é Affonso Ávila (1975:29-36), que localizou na literatura barroca a fase de apropriação da linguagem e da realidade: em um primeiro momento (século XVII e primeira metade do século XVIII), como simples apêndice da literatura portuguesa; mas no chamado grande barroco do final do séc. XVIII, com Gregório de Matos, o "Boca do Inferno", é tempo de um homem europeu tropicalizado reagir ao instrumento lingüístico de que se apropria. A linguagem exuberante da poesia (típica do barroco: ora erótica, ora espiritualizada), em perfeita sintonia com a exuberância tropical, na busca de uma fantasia autônoma.

Gregório de Matos lírico - compilação: Dantas (1979: 183):

Tu, que em um peito abrasas escondido;

Tu, que em um rosto corres desatado; Quando fogo, em cristais aprisionado; Quando cristal, em chamas derretido

Poesia sacra do "Boca do Inferno" - compilação: Dantas (1979: 184):

Eu sou, Senhor, a ovelha desgarrada, Cobrai-a; e não queirais, pastor divino,

Perder na vossa ovelha a vossa glória.

E, o grande sucesso, o satírico - compilação: Dantas (1979: 182):

Noutras obras de talento

Só eu sou o asneirão.

Mas, sendo sátira, então

Só eu tenho o entendimento.

No romantismo, o processo de posse da linguagem, na fundação do mito autóctone; perfeitamente exemplificável na estética de José de Alencar, o escritor de folhetins no Correio Mercantil e autor de romances indianistas, como Iracema, Ubirajara e O Guarani, e regionalistas, como O Sertanejo e O Gaúcho. Segundo Agripino Grieco: ${ }^{8}$

Iracema e Ubirajara são trabalhos em que a música luta com a prosa, tudo quer ser melodia pura. (...) É a parte mítica de um Brasil sem heróis de carne e osso em condições de competir com esses heróis de sonho... Grande Alencar! $\mathrm{Na}$ "cadência bonita" de uma língua brasileira, a presença dos mitos de origem - a perfeita harmonia racial no país e o sincretismo religioso: Ceci apaixona- 
se pelo índio Peri e promete-lhe o céu cristão.

José de Alencar, O Guarani. (compilação: Dantas, 1979: 213):

Sobre aquele azul que tu vês, continuou ela, Deus mora no seu trono, rodeado dos que o adoram. Nós iremos lá, Peri! Tu viverás com tua irmã, sempre!...

Ela embebeu os olhos nos olhos do seu amigo, e lânguida reclinou a loura fronte. $O$ hálito ardente de Peri bafejou-lhe a face. Fez-se no semblante da virgem um ninho de castos rubores e lânguidos sorrisos: os lábios abriram como asas purpúreas de um beijo soltando o vôo.

O realismo, na lapidação final da linguagem, é a ponte para o discurso modernista. Tematicamente exaurida, a nossa persona romântica transmuta-se e amadurece: dos lábios de mel de Iracema aos olhos de ressaca de Capitu. Machado de Assis $^{9}$ continua a tradição iniciada por Alencar de localizar nas personagens femininas um conceito de Brasil.

Em Dom Casmurro, Dominique Fernandez (1996: 191) leu a covardia de Bentinho diante da suspeita da traição de Capitu - suspeita que não desencadeia nenhum desejo viril de investigação, mas flutua em seu espírito como um veneno com o qual se deleita - , mas não reparou na "acusada", a quem os críticos menores da literatura brasileira submeteram a verdadeiros tribunais, com direito a "advogados de defesa" e "promotores de acusação": Capitu traiu ou não traiu?

O Brasil já não é a doce donzela, cujos lábios têm gosto de mel. Adulta, nossa persona é fugidia, não é Madame Bovary, que, deixa claro Flaubert, traiu o marido. Barroca e não cartesiana, definida na dúvida, vê e é vista pelo mundo com olhos de ressaca. Pois é, parece que o Brasil sempre foi barroco? e pós-moderno!? e, em que pesem os tantos (e belos) torsos nus registrados pela câmara de Ferrante Ferranti, feminino. Há que se recorrer à psicanálise (Ruth Brandão-1996: 72):

Se o feminino não se representa [segundo Lacan], se não há letra de sua inscrição no inconsciente, esse conceito, entretanto, propicia que se pensem os impasses da representação (...) Se se perderam ou se esvaneceram os alicerces de uma origem fundadora (...), se se desconstruiu a metafísica, e a linguagem se constitui como contornando um vazio, às bordas de um real que não se diz, sempre apontando ou encobrindo o não-todo de uma verdade que está sempre se construindo, então o feminino é o lugar privilegiado para se pensarem essas questões.

No modernismo, é instaurado o processo de reflexão, que desconstrói o mito, satirizando-o. Macunaíma, de Mário de Andrade, um herói sem nenhum caráter, festeja a indolência nacional, repetindo: "Ai, que preguiça". Uma incipiente desconstrução lingüística ("milhor" em vez de melhor) prenuncia, entretanto, o processo que se consolidará no pósmodernismo, que, na falta de melhor expressão para caracterizar essa fase (já que a obra de Ávila, referência desta classificação, encerra-se no período modernista), nomina-se: processo de fruição. E é na desconstrução mesma da norma culta da língua que se instaura a temática - música e letra da canção inaugural da pós-modernidade: Grande Sertão: Veredas.

Reflexões como a de Affonso Ávila, pela profundidade e contextualização, tornam perfeitamente dispensável o contemporâneo approach europeu aos temas barrocos nacionais, a não ser do ponto de vista do marketing: para legitimar a teoria literária brasileira e, quiçá, para 
incrementar a venda de livros. Parodiando Baudrillard: a Nova Ordem européia vem apropriar-se do barroco ali onde ele sangra.

\section{O novo no arcaico}

De acordo com Dacanal (1988: 23), Grande Sertão: Veredas se não é o maior romance brasileiro de todos os tempos - porque então teríamos que ignorar a grandeza de Machado [o "velho", no dizer do jovem e inteligente jornalista brasileiro ${ }^{10}$ - é o novo, ou o que produz estranhamento, através da linguagem, da temática, da estrutura narrativa e do gênero.

A linguagem, consolidando a linha crescente iniciada no barroco - do movimento de apropriação da língua portuguesa pelos sujeitos que falam no Brasil -, é completa ruptura, desconstrução da norma culta, na ousada aventura sonora de reprodução do falar sertanejo.

Região ignorada pela cultura então europeizada"1 da costa brasileira - o "Sul Maravilha", como diziam as personagens nordestinas do saudoso cartunista Henfil: o Bode Francisco Orellana e a Graúna -, é natural que a língua do centro-oeste se desviasse do português falado pelos grupos sociais dominantes, criadores e detentores dos cânones oficiais da gramática, cujo acento determinava a grafia.

Este o aspecto que provocou o maior impacto, quando do surgimento de Grande Sertão, em 1956: o caboclo, sem livros e sem gramática, invadiu a praia dos doutores, passando a ser "ouvido", na perfeita transcrição fonética do sotaque sertanejo que realizou Guimarães Rosa. Essa, a ruptura. A urdir o estranhamento, o "método roseano"; que o escritor revela a Lorenz (1973: 338):

Primeiro, há meu método que implica a utilização de cada palavra como se ela tivesse acabado de nascer, para limpá-la das impurezas da linguagem cotidiana e reduzi-la a seu sentido original. Por isso, e este é o segundo elemento, eu incluo em minha dicção certas particularidades dialéticas de minha região, que não são linguagem literária e ainda têm sua marca original, não estão desgastadas e quase sempre são de uma grande sabedoria lingüística.

Primeira obra literária a fixar, com visão intrínseca (melhor seria dizer "com audição"), a temática caboclo-sertaneja brasileira, Grande sertão: veredas evidencia o caráter extrínseco das românticas tentativas anteriores. Região desligada da modernidade racionalista dos núcleos urbanos, o centro-oeste de Riobaldo é o Brasil arcaico, do coronelismo, da jagunçagem, do cangaço, que reflete essa cultura no momento mesmo em que ela marcha para a extinção, na integração tardia ao processo de expansão do incipiente (e dependente) capitalismo brasileiro.

De fato, até a $1^{\text {a }}$ Guerra Mundial a economia nacional girava em torno do "complexo cafeeiro". O conflito mundial e sobretudo a crise de 1929 foram os principais fatores do colapso do modelo agrário-exportador que o Brasil herdara da colônia. O novo caminho do desenvolvimento era o da diversificação da economia, com especial ênfase à industrialização, cuja meta era a substituição das importações.

Getúlio Vargas dá início a um programa de industrialização, que, sob o comando do Estado, é voltado para o investimento em infra-estrutura e indústria pesada. Durante a $2^{a}$ Guerra criaram-se as condições favoráveis a tais programas; através de empréstimos externos, Vargas implanta a Usina de Volta Redonda e a Companhia do Vale do Rio Doce, e, em 1938, cria o Conselho Nacional do Petróleo, concretizando o sonho de Monteiro Lobato: o "petróleo é nosso".

Porém Vargas nada fez para de 
fato alterar a estrutura fundiária no país, limitando-se a transferir capital para a indústria, acirrando o contraste entre o desenvolvimento industrial-urbano e o empobrecimento do campo. Barroco, sustenta o paradoxo desenvolvimento econômico e ditadura política: em tempos de fascismo dos duces, o doce fascismo do "pai dos pobres".

O governo de Juscelino Kubitschek (1956-1961) desencadeou um acelerado crescimento da produção ("50 anos em 5" era o lema de campanha do Presidente), e a concretização de tal meta envolveu vultosos investimentos estatais em infra-estrutura e na dinamização do setor de bens de produção. Incentivos fiscais e creditícios convidavam os investidores estrangeiros (com seus sofisticados produtos de consumo) a invadir o gigantesco mercado interno em expansão. A liberação de trabalhadores do setor primário para a economia urbana forneceu um estoque de mão-de-obra pouco qualificada, mas barata. $O$ modelo econômico do país, já então apoiado na compressão de salários e na maximização de lucros, foi respaldado pela massa de migrantes rurais, geradas pelo avanço rápido e homogeneizador das estruturas urbanas sobre as veredas do Brasil.

À época da ditadura militar (19641985), situação idêntica - a "integração" da Amazônia ("integrar para não entregar" era o lema da propaganda oficial) - vai refletir na criação artística brasileira, desta vez no cinema: em Bye-bye Brasil, a "Caravana Rolidei" despede-se das estruturas arcaicas, levando seu pueril espetáculo para longe das "espinhas de peixe" (as antenas de televisão, que passaram a "integrar" o Brasil, notadamente a partir dos anos 70).

Fator de inovação em Grande Sertão: Veredas, também apontado por Dacanal (1995: 24-26), é a estrutura narrativa. A onisciência da primeira pessoa de Riobaldo conta, entretanto, com a presença de um interlocutor: o doutor. Mudo representante do segmento letrado, registra em uma caderneta a tradição de uma cultura oral, no momento em que ela está em vias de extinção (O MUNDO QUER FICAR SEM SERTÃO). O relato de Riobaldo, não linear, fora de uma ordem seqüencial, encontra mesmo identificação com as narrativas orais, quase dramatúrgicas, em disposição que privilegia o inventário interpretativo da vida do exjagunço.

Ao tratar dos deslizes da tradução francesa de Grande Sertão: Veredas, Dominique Fernandez (1996: 110) identifica, com propriedade, o gênero épico na obra, que, assim, não poderia receber como título o nome de uma personagem secundária: Guimarães Rosa não quis escrever a história de um homem, mas a epopéia do Brasil. De fato, a epopéia, se não do Brasil, de um dos Brasis: o sertão. De acordo com o depoimento do escritor a Lorenz (1973: 353): Riobaldo não é Fausto, e menos ainda um místico barroco. Riobaldo é o sertão feito homem e é meu irmão.

Dacanal (1995: 28-30) contextualiza a travessia interior de Riobaldo na passagem de um mundo de estruturas conscienciais mítico-sacrais, primitivo, para o mundo de uma consciência reflexiva.

De fato, é possível ler a obra como um espaço (e tempo) de tensão permanente entre o arcaico e o moderno, o rural e o urbano, o oral e o escrito. É do movimento pendular entre esses pólos que surge, mapeado, o sertão e seus habitantes. Já no plano lógico-racional, Riobaldo conclui: VIVER É MUITO PERIGOSO.

Epopéia do avançar do Brasil litorâneo, das urbes e de sua organização social e mental contra o sertão; o que resultará na destruição do arcaico pelas estruturas conscienciais dessacralizadas, pragmáticas, racionalistas e capitalistas, próprias do mundo urbanizado. Riobaldo é o produto ambíguo dessa passagem e sua travessia só se completa na última frase do livro. Se é que se completa, porque o romance termina (como começara) com o 
sinal de infinito.

Do início da narrativa de Riobaldo ao doutor (no presente) das peripécias dos tempos de jagunçagem (acontecidas no passado), até o final conclusivo - Riobaldo apaziguado pelo reumatismo e pela prosperidade, consolidando sua visão de mundo lógica e racionalmente - a ambigüidade é tema recorrente: O diabo existe ou não? Se existe, houve pacto? Riobaldo vendeu sua alma, há um episódio fáustico? Riobaldo amou Diadorim ou Maria Deolinda? Epopéia do sertão, das dualidades barrocas de uma travessia que se funda na incerteza que o novo mundo - moderno - traz ao herói.

\section{Civilização Oral}

Novamente Dominique Fernandez (1996: 198) "acerta a mão":

É verdade que no Brasil a literatura ocupa apenas um lugar subalterno; civilização do corpo, não da escrita; um poeta, para ter audiência, deve ser primeiro compositor de música e cantor.

\section{Historicamente instrumento} de aquisição de conhecimento de diferenciação da elite em relação à massa, a literatura, nesse recorte, foi o registro do pulsar do corpo social até a segunda década do século $X X$.

Com a Semana de Arte Moderna, em 1922, outra arte - a pintura - insinuase nessa até então hegemônica função de representação da alma brasileira. Nada muda, no entanto, quanto ao segmento produtor e receptor da expressão artística no Brasil.

A música, por seu turno, até a década de 40 permaneceu cindida entre peças eruditas - de temática nacional, mas suficientemente europeizadas para atender à demanda das elites (exemplo dessa estética é O Guarani, de Carlos Gomes)
- e as modinhas e lundús que deram origem ao chorinho (Chiquinha Gonzaga) e aos primeiros sambas, estigmatizados nas favelas e no gosto popular.

Com o surgimento dos meios de massa - rádio e cinema - porém, a cultura popular passa a ter seus veículos. O rádio afirma seu caráter comercial na sociedade urbano-industrial emergente, tornando-se, nas décadas de 40 e 50, espetáculo voltado para a massa. 0 que não impediu, entretanto, que a programação das emissoras de então - que já cobriam todo o território nacional através de ondas curtas e médias formada por humorísticos, noticiosos, radionovelas e programas de auditório, especialmente musicais, contasse com a presença de autoridades - Vargas inclusive - na platéia dos seus auditórios em freqüentes "ocasiões especiais". ${ }^{12}$

Também na era Vargas, com a ampliação da rede escolar, a alfabetização perde a aura de privilégio, mas a literatura permanece restrita aos círculos da elite, diferenciada agora (e cada vez mais) pelos títulos universitários, inatingíveis para a maioria da população.

Nos anos 60, o cinema novo, a bossa-nova e o tropicalismo sinalizam o surgimento de uma nova elite artística que, adaptada à era dos mass media, apropriase das tradicionais formas de expressão popular, sofisticando-as e conferindo-Ihes status intelectual. Nos anos 70, a música popular brasileira adquire a "aura" - no sentido dado ao termo por Walter Benjamin - que distingue as obras de arte, ungida na resistência ao regime militar.

Tal estado de coisas - e Chico Buarque, Caetano Veloso e Gilberto Gil - mantém-se até hoje, convivendo agora, é verdade, com a "breguice" regressiva da indústria cultural da pós-modernidade, cuja conseqüência é a volta da separação entre produção artística dirigida à elite ou às massas.

Pouco sedimentada, inclusive por uma questão de tempo - a literatura 
brasileira só adquirira a maioridade na eclosão do romance do século XIX - a tradição literária nacional não resiste à avalanche da nova intelectualidade artística (especialmente a musical), que transforma mesmo a classe média universitarizada em não-leitores.

Exemplo disso, a ausência de reação do público do seminário, quando da afirmação de Dominique Fernandez sobre a homossexualidade da relação Riobaldo/ Diadorim, abortada por Guimarães Rosa. Explica-se: a maioria do público, formado por universitários e pós-graduandos em comunicação, talvez não tenha lido sequer a obra máxima da literatura brasileira. Que pena, ela já não é mais a minha pequena!

Enfim, para as perguntas sem respostas convém evitar conclusões bombásticas, fazer uso do pensamento complexo preconizado por Morin, para apreender a simplicidade de Guimarães Rosa (1984: 467), pérola perfeita deste Brasil desde sempre barroco:

Todos os meus livros são simples tentativas de rodear e devassar um pouquinho o mistério cósmico, esta coisa movente, impossível, perturbante e rebelde a qualquer lógica, que é a chamada realidade, que é a gente mesmo, o mundo, a vida. Antes o absurdo que o óbvio, que o frouxo. Toda lógica contém boa dose de mistificação. Toda mistificação contém boa dose de inevitável verdade.

\section{Anexos}

Um chamado João

Por que João sorria/se the perguntavam/que mistério é esse?/E propondo desenhos figurava/menos a resposta que/outra questão ao perguntante?

Tinha parte com... (não sei/o nome) ou ele mesmo era/a parte de gente/ servindo de ponte/entre o sub e o sobre/que se arcabuzeiam/de antes do princípio,/que se entrelaçam/para melhor guerra,/para maior festa?

Ficamos sem saber o que era João/e se João existiu/de se pegar.

(Fragmento do poema "Um chamado João", de Carlos Drummond de Andrade)

João Guimarães Rosa nasceu em 27 de julho de 1908, em Cordisburgo, Minas Gerais. Passou a infância a ouvir as histórias de Juca Bananeira, o negro que the contava sobre boiadeiros e jagunços. Graduou-se em Medicina, em Belo Horizonte, e trabalhou em várias cidades do interior mineiro; de caderneta em punho, atento à paisagem e às gentes. Nessa época, publica contos na revista $O$ Cruzeiro.

Estudou sozinho alemão e russo e era também o sofisticado leitor de uma gama extensa de assuntos, como zoologia, heráldica, religião, literatura, filosofia, pintura.

$\mathrm{C} \circ \mathrm{mo}$

diplomata (em 1934 prestou concurso para o Itamaraty), correu mundo: Rio de Janeiro, Paris, Bogotá, Hamburgo. No entanto, para a obra de Guimarães Rosa, duas outras viagens são de fato fundamentais: em 1945, volta ao interior de Minas, a passeio, e, em 1952, acompanha a condução de uma boiada pelo sertão. Publica Corpo de Baile e Grande Sertão: Veredas, em 1956.

Em 16 de novembro de 1967, tomou posse na Academia Brasileira de Letras; três dias depois, em 19 de novembro, morreu no Rio de Janeiro. Aliás, as pessoas não morrem, ficam encantadas. ${ }^{13}$

\section{Notas}

1 Fala final de Riobaldo, no romance Grande sertão: veredas, de João Guimarães Rosa, p. 465 da edição citada nas Referências. Todas as demais citações da obra estarão grafadas em "caixa-alta". 
2 Dominique Fernandez. O ouro dos trópicos, p. 112.

$3 \quad$ Idem, ibidem.

$4 \quad$ Idem, p. 110.

$5 \quad$ Idem, p. 111.

$6 \quad$ Na entrevista a Lorenz (1973:336), em janeiro de 1965, na cidade de Gênova.

7 Dominique Fernandez, op. citada, p. 112.

$8 \quad$ Citado por José Maria de Souza Dantas, Novo manual de literatura, p. 212.

9 Dominique Fernandez (1996:191) declara: Assim como o homem evitava, ao falar, longos períodos por receio de tropeçar, o romancista se protege nas frases de uma ou duas linhas, com freqüência menos. A afirmativa é falsa, a análise sintática de longos períodos machadianos é prática comum ao ensino da língua portuguesa.

10 Referido em Dominique Fernandez, op. citada, $p$. 189.

11 Mas já em vias de se tornar, mais e mais, americanizada; fenômeno que, de resto, invadiu o mundo a partir da $2^{a}$ Guerra Mundial, com a rendição dos países do Eixo e quicá de toda a Europa Ocidental à pax americana.

12 Sônia Virgínia Moreira, Rádio Palanque, p. 34.

13 Declaração de Guimarães Rosa, em seu discurso de posse na Academia Brasileira de Letras.

\section{Referências}

ÁVILA, Affonso. O modernismo. São Paulo: Perspectiva, 1975.

BAUDRILLARD, Jean. Tela total. Porto Alegre: Sulina, 1997.

BRANDÃO, Ruth Silviano. Literatura e psicanálise. Porto Alegre: UFRGS, 1996.

CHIAMPI, Irlemar. 0 realismo maravilhoso. São Paulo:
Perspectiva, 1980.

DACANAL, José Hildebrando. Nova narrativa épica no Brasil. Porto Alegre: Mercado Aberto, 1988.

1995. . Era uma vez a literatura. Porto Alegre: UFRGS,

DANTAS, José Maria de Souza. Novo manual de literatura: Análise de textos literários e não literários. Rio de Janeiro: Difel, 1979.

FERNANDEZ, Dominique. 0 ouro dos Trópicos: Passeio pelo Portugal e o Brasil barrocos. Porto Alegre: Sulina, 1996.

FREYRE, Gilberto. Heróis e vilões no romance brasileiro: em torno das projeções de tipos sócio-antropológicos em personagens de romances nacionais do século XIX e atual. São Paulo: Cultrix/Edusp, 1979.

JOSEF, Bella Karacuchanski. História da literatura hispanoamericana. Rio de Janeiro: Francisco Alves, 1989.

LORENZ, Günter W. Diálogo com a América Latina: panorama de uma literatura do futuro. São Paulo: E.P.U., 1973.

MOREIRA, Sônia Virgínia. Rádio Palanque - fazendo política no ar. Rio de Janeiro: Mil Palavras, 1998.

MORIN, Edgar. O Método I. A natureza da natureza. (S.L.): Europa-América, (S.D.)

."Da necessidade de um pensamento complexo". In MARTINS, Francisco Menezes e SILVA, Juremir Machado da. (org.) Para navegar no século XXI - Tecnologias do imaginário e cibercultura. Porto Alegre: Sulina/Edipucrs, 1999.

ROSA, João Guimarães. Grande sertão: veredas. São Paulo, Nova Fronteira, 1984.

VASCONCELOS, Sandra Guardini Teixeira. Os mundos de Rosa. http://www.klickescritores.com.br/imortais.htm

VILLAÇA, Nízia. Paradoxos do pós-moderno: sujeito \& ficção. Rio de Janeiro: UFRJ, 1996. 